\title{
The Progress of Sri Lanka's Renewable Energy Sector Developments in Mitigating the GHG Emission
}

\author{
Withanaarachchi A.S , Nanayakkara L.D.J.F, Pushpakumara C. \\ Department of Industrial management, University of Kelaniya, Sri Lanka \\ *Corresponding Author: amila.green@gmail.com
}

Copyright $@ 2014$ Horizon Research Publishing All rights reserved.

\begin{abstract}
Though Sri Lanka's current carbon footprint is much less than the global vale, the country's existing and planned economic developments which in turn raised the demand for power has resulted an increase in GHG emission. The GHGs are emitted mostly by burning of fossil fuels for energy generation including transport. Thus one of the most effective ways of reducing emissions is to use renewable energy sources. The purpose of this study is to evaluate the current phase of development in Non-Conventional Renewable Energy (NCRE) source based electricity generation and its contribution to in the mitigation of $\mathrm{GHG}$ emission in Sri Lanka. Literature reviews and expert interviews were mainly used as the primary tool for this study. The current government policies have given a target of $20 \%$ renewable energy by 2020 . Though the relevant authorities have taken considerable measures to encourage small power producers, it is the economic and practical realities that are holding back the development of renewable energy sector to reach the said targets by 2020 . Government's decision to phase out dependence on oil for electricity generation and coal being the least cost option has driven the future generation to depend on coal fired power plants. However, Energy Balance 2011 has shown that the introduction of coal power plant has already escalated the country's $\mathrm{CO}_{2}$ emission. Thus to prevent Sri Lanka being a significant mark in the world map of carbon footprint, immediate measures should be taken at least to reach the current renewable energy targets by 2020 .
\end{abstract}

Keywords GHG, Renewable Energy, Sri Lanka, Hydro Power, Wind Energy, Biomass, Solar Systems

\section{Introduction}

The 'Energy' the primary building blocks of any nation's development changed its dimensions rapidly over the past few years as a response to increasing environment and financial concerns. The identification of the year 2012 as the year of Sustainable energy for all indicates importance of green Technology in today's context. However, as of 2010 only $16.7 \%$ of global energy consumption was generated by renewable energy resources (REN21 Global Status Report, 2012: 13). As per the International Energy Agency (in Pueyo and Linares, 2012: 6) the unprecedented levels of economic growth emerging in the developing nations will make them responsible for future growth in energy demand and greenhouse gas (GHG) emissions. Based on International Energy Agency 2009 report (in Benioff et al, 2010: 8), rapidly growing energy demand in developing countries is projected to double by 2030 .

Access to energy has an important impact on long-term poverty reduction in developing countries (Kolk and Buuse, 2012: 552). By now many developing nations and countries in transition's energy mix has been largely dominated by fossil fuels. Today overdependence on fossil fuels has forced the world to consider global warming and climate change via greenhouse gas a striking issue which needs immediate and long term measures to overcome a foreseeable tragedy.

In 1995 Sri Lanka produced $95 \%$ of the grid electrical energy needs from conventional hydro power plants. However, expansion of household electricity and the boost in the industrial sector of the country have forced the country to depend on alternative energy resources such as fossil fuels. 'In the year 2010, Sri Lanka produced 53.38\% the total electricity requirements from renewable energy sources, out of which $46.56 \%$ accounted for large hydro and the rest $6.83 \%$ were born by Non-Conventional Renewable Energy (NCRE) Sources which comprised of small hydro, wind power, biomass and solar (large hydro: 46.56\%, new renewables 6.83\%)' (SLSEA On-grid Renewable Energy Development, 2011:4).

\section{Research Objectives}

Considering the fact that Sri Lanka's large reserves of hydro power have already been utilized, the CEB had diversified to thermal power, resulting in a gradual shift in the industry power mix (RAM Report-Sri Lankan Power sector, 2012:4). Though the Sri Lanka's current carbon foot print is much less than the global value, the country's existing and planned economic developments which in turn 
raise the demand for power has resulted an increase in the GHG emission. Based on the published data energy sector is the main contributor to the $(65 \%)$ GHG emission. Sri Lankan authorities have identified the foreseeable threat in advance and have taken mitigating measures in all the sectors including energy (Ranasinghe, 2012: 290). Especially the policy decision to escalate the NCRE based electricity generation is very impressive and the targets are on par with the targets set by developed countries. However gaps between the set targets and the current progress in the sector have created many doubts. Thus the purpose of this study is to evaluate the current phase of development in NCRE based electricity generation and its contribution to the mitigation of GHG emission in Sri Lanka.

\section{Methodology}

To effectively address the research questions and objectives, a qualitative, exploratory and descriptive research design presented the most viable approach. Thus in this study, the research process was approached in two phases. In the initial phase literature related to the government publications, policy papers and local academic publications were studied to explore the present energy situation of the country. International energy reports and international academic journals were studied to explore the potentiality of renewable energy sector and to ascertain the international developments in the clean-energy sector. In the second phase, experts including government officials, academics and private investors pertaining to Sri Lankan renewable energy sector were interviewed to gain an insight into the challengers that the country needs to overcome in attaining the said targets in the renewable energy sector.

\section{Analysis and Results}

\section{Rising Demand}

Figure 1 demonstrates the gross electricity usage and generation for the past 12 years. Ceylon Electricity Board Long Term Generation Expansion Plan shows that the energy demand has been growing at an average rate of $5.9 \%$ per annum (CEB - Long Term Generation Expansion Plan, 2011:3-1). Deriving the benefits of the peace situation of Sri Lanka the demand for power is expected to accelerate in the foreseeable future.

Although the total grid connected capacity increased to 3,140.7 MW in 2011 from 2,817.6 MW in 2010 (SLSEA Sri Lanka Energy Balance, 2011: 60), it has been presumed that with the current escalating demand, the need for electricity will be doubled by 2020 compared with 2010 figure, more precisely 5,430 MW by 2020 (RAM Report-Sri Lankan Power sector, 2012:7).

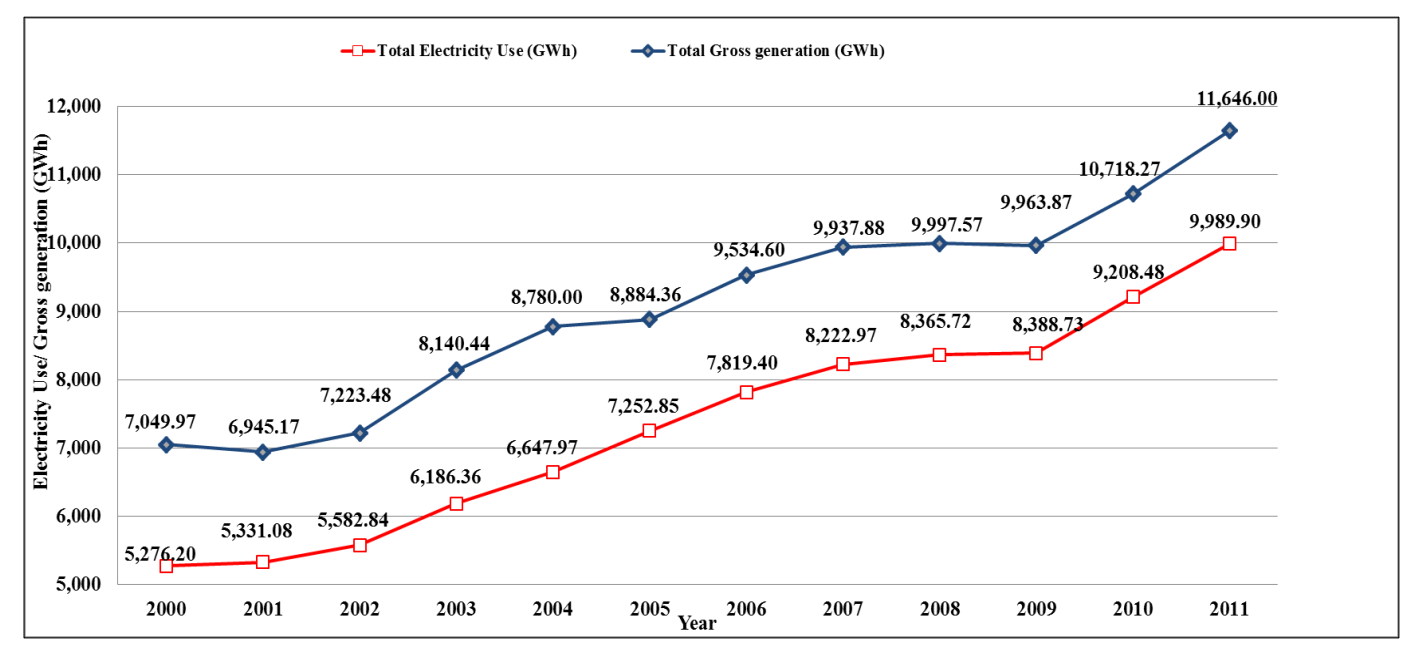

Figure 1. Electricity Usage Vs. Gross Generation 


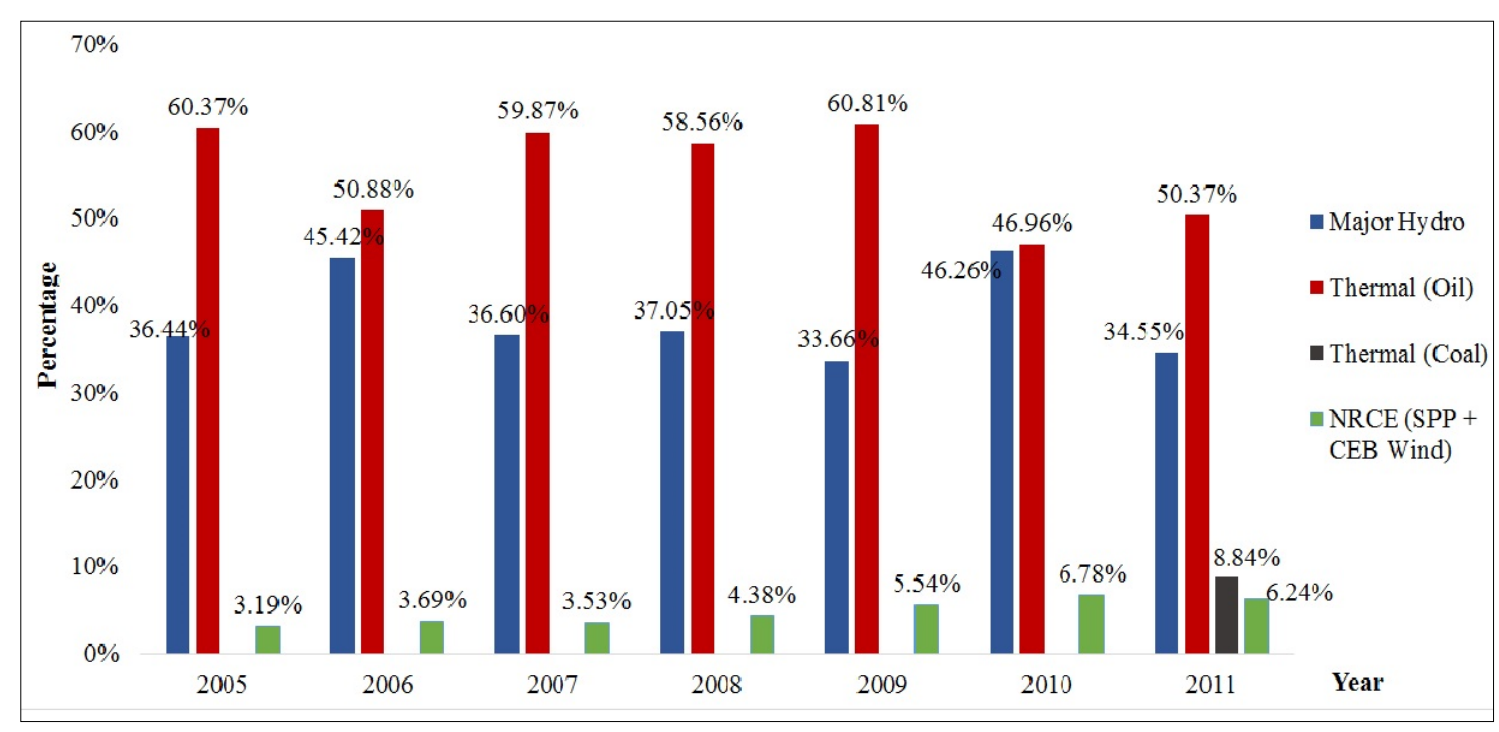

Figure 2. Gross Generation to Grid as a percentage of Total Production

\section{Electricity Generation Power Mix}

Figure 2 exhibits the gross generation to the grid from different energy sources for the past few years. These statistics show that it is the thermal oil which is the highest contributor for the nation's electricity generation, followed by the major hydro.

But the contribution of major hydro has been varied with the fluctuation in the rain fall. NCREs contribution has been gradually increased over the past few years. However, with the introduction of the Norochcholai $300 \mathrm{MW}$ power plant in year 2011, the contribution of NCRE has started to decline.

Based on the installed capacity, Thermal power sources which comprise oil and coal account for $54 \%$ of the total installed capacity of Sri Lanka. While the major hydro account for $38 \%$ of the total capacity the NCRE has a presence of only $7.8 \%$. If we take the NCRE alone it is again the mini hydro that is the highest contributor (Refer Table 1) to the renewable energy sector followed by wind and biomass. The presence of solar for the national grid was minimal by year 2011. The dependency on mini hydro sector has driven the NCRE based electricity generation to depend on the rain fall, which in turn encourages the thermal sources to be used in dry seasons.

Table 1. Installed capacities and generation of NCRE power plants by end 2011 (Energy Balance, 2011)

\begin{tabular}{c|cccc}
\hline $\begin{array}{c}\text { Type of } \\
\text { power } \\
\text { stations }\end{array}$ & $\begin{array}{c}\text { Number } \\
\text { of plants }\end{array}$ & $\begin{array}{c}\text { Total } \\
\text { Capacity } \\
\text { (MW) }\end{array}$ & $\begin{array}{c}\text { Generation } \\
\text { in year } \\
2011(\mathrm{GWh})\end{array}$ & $\begin{array}{c}\text { Share in } \\
\text { generation } \\
(\%)\end{array}$ \\
\hline $\begin{array}{c}\text { Small } \\
\text { Hydro }\end{array}$ & 92 & 193.6 & 600.6 & 83.2 \\
Wind & 5 & 33.2 & 89.0 & 12.3 \\
Biomass & 4 & 12.5 & 31.6 & 4.4 \\
Solar & 4 & 1.4 & 1.1 & 0.2 \\
\hline
\end{tabular}

\section{New renewable energy targets}

Based on the installed capacity, NCRE accounts for 7.7\% of the total grid connected capacity (SLSEA Sri Lanka
Energy Balance, 2011: 26). Irrespective of the current situation the renewable energy sector of Sri Lanka, the authorities have taken an impressive policy decision to lift the renewable energy sector. According to the strategies laid out by the National Energy Policies and Strategies, new renewable energy development is carried out in the country with the aim of increasing the stake of NCRE in power generation by $10 \%$ by 2015 . The goal is to further extend to $20 \%$ of renewable energy by 2020 as per the 'The development policy framework government of Sri Lanka Mahinda Chinthana, The way forward (SLSEA Sri Lanka Energy Balance, 2011: 102).

An expert interview that has been conducted with the relevant authorities has come up with the following goals (Table 2) for the respective renewable energy sources. The Table 2 lists down the respective targets along with the 2011 figures (based on Energy Balance 2011).

Table 2. Proposed Targets for the NCRE Power Sector

\begin{tabular}{c|ccc}
\hline NCRE & 2011 & 2015 & 2020 \\
\hline Small Hydro & $193.6 \mathrm{MW}$ & $330 \mathrm{MW}$ & $400 \mathrm{MW}$ \\
Wind & $33.2 \mathrm{MW}$ & $85 \mathrm{MW}$ & $401 \mathrm{MW}$ \\
Biomass & $12.5 \mathrm{MW}$ & $40 \mathrm{MW}$ & $153 \mathrm{MW}$ \\
Solar & $1.4 \mathrm{MW}$ & $5 \mathrm{MW}$ & $161 \mathrm{MW}$ \\
\hline As a $\%$ & $7.66 \%$ & $10 \%$ & $20 \%$ \\
\hline
\end{tabular}

If we are to look at the progress by year 2012, small hydro installed capacity lies at $224 \mathrm{MW}$; wind has reached $74 \mathrm{MW}$ and the biomass and solar lies at $12.5 \mathrm{MW}$ and $1.4 \mathrm{MW}$ respectively. So the current NCRE adds up to $312 \mathrm{MW}$. To reach the target by 2015, we need further $150 \mathrm{MW}$ to $200 \mathrm{MW}$ of installed capacity (which will sum up to 455 to $500 \mathrm{MW}$ by 2015). Considering the projects which are in the pipeline at various stages of approval which will become operational (Mini hydropower - $259 \mathrm{MW}$; Dendro power - $28 \mathrm{MW}$; Wind power $-74 \mathrm{MW}$ and Waste to energy $-183 \mathrm{MW}$ ), the $10 \%$ contribution from NCRE sources could be achieved by 
2015 with some effort (Ranasinghe, 2012: 292).

$20 \%$ renewable energy by 2020 is a target that is being debated among experts in the industry. CEB's long-term generation plan targets a capacity of 5,430 MW by 2020 (RAM Report-Sri Lankan Power sector, 2012:6). Thus 20\% of stated capacity comes to around 1,100 MW.

\section{Year 2020 targets for Small Hydro}

Hydro power being a very mature and saturated industry in the Sri Lankan power sector and the fact that the country has considerable amount of potential sites for that matter will enable the hydro power to reach the said targets. If the said targets were reached by 2015, then we would need further $150 \mathrm{MW}$ within the next 5 year period to reach the targets by 2020.

\section{Wind power targets to be reached by 2020}

Wind being the fastest growing renewable energy source in the world holds the 2nd position in the NCRE sector of Sri Lanka. Wind took a lead in the NCRE sector primary due to the attractive tariff that has been proposed by the Public Utility Commission of Sri Lanka(PUCSL). Wind being a considerably new industry to Sri Lanka, we have to import the technology from other parts of the world. The technology has been rapidly growing in our neighboring country India, which enables us to have an easy supply chain. By the end of the year 2012 the installed capacity was 74MW. Reaching the said targets by 2020 would require more than $300 \mathrm{MW}$ to be installed in the next 5 year period. Studies have claimed that Sri Lanka has higher potential for generating electricity via wind power with a plant factor reaching $32 \%$ in some areas. (PUCSL Proposed Non-Conventional Renewable Energy Tariffs, 2012: 3). However, favorable the conditions that are there in the industry, there are certain limitations that might prevent Sri Lanka to reach the said target by 2020 . Compared with hydro power plants the time taken to install a wind power plant is very much less, but Wind Power Association of Sri Lanka claims that capital cost of a small wind power plant is higher than 254 million rupees per MW (PUCSL Proposed Non-Conventional Renewable Energy Tariffs, 2012: 7). Wind is not a steady resource; the wind flow throughout the day in a given site varies drastically. This unpredictable nature of the wind has forced the CEB to temporarily hold further absorption of electricity from the wind sources. Thus irrespective of the permission that has already been granted for new wind power plants these limitations might hold further development of wind resources and thus attaining the said target by 2020 will be a challenge.

\section{Biomass targets by 2020}

Biomass is the most common source of energy supply in the country (SLSEA Sri Lanka Energy Balance, 2011: 17), but its contribution to the generation of electricity is very minimal compared to the other NCRE sources (share of generation by end of 2011 was only $4.4 \%$ out of total NCRE). Internationally biomass has a very wide spectrum in solid, gas and liquid form (REN21 - Global Status Report, 2012). However, in Sri Lankan context we will be looking at solid biomass for electricity generation. Most common form of biomass available in Sri Lanka comes in the forms of fuel wood, municiple/industrial and agricultural solid waste (SLSEA Sri Lanka Energy Balance, 2011:17). If we consider the tariff that has been granted for biomass based electricty generation, it is very much on par with wind. But it is not the price that holds the development of biomass sector. There are technical, practical and business realities that affect the sector's survival. Biomass requires lot of primilinary steps to be followed (growing, harvesting, choping, drying and feeding) in order to get it going and generate electricty. In Sri Lankan context the lack of consistent supply chain mechanisams that support continuous generation of electricity via biomass is the major concern. Thus irrespective of attractive tariff that is being granted for biomass based electricty generation practical realities will hold the biomass to reach the said target by 2020

\section{Solar Power by 2020}

Attaining 2020 target in seven years' time itself is a challenging target, when considering the current progess in the solar powered power plants in Sri Lanka (only 1.4MW installed in two pilet power plants in Hambanthota). However, irrespective of the fact that the provisional approval has been given to reach 52MW of installed capacity, there are again many more challenges to be overcome to reach the said target. Similer to wind power sector high fluctuation in the generation of electricty due to varying sun light in a given site will affect the amount that can be absorbed to the national grid. Another limitation for the sector growth is the capital requirement. Though the sun light is free, capital is not free. Some investors claim that capital cost for solar is high as LKR267Mn per MW (PUCSL Proposed Non-Conventional Renewable Energy Tariffs, 2012:7). Thus based on current cost figures it will be a challenge to attract investors in the solar power sector to generate electricity to feed the national grid. On top of these concerns requirement of abundant land area to generate sufficient electricity will be an added issue for solar to escalate in the near future.

\section{Survey questionnaire}

Based on the above discussion current phase of developments in the Sri Lankan NCRE sector will not be sufficient to reach the renewable energy target set for the year 2020. The authors further extend the study to identify the most import factors that is crucial for the development of renewable energy sector of the country. Thus the factors which were highlighted in the initial interviews were formed into a survey questionnaire. The pool of factors which consider to be important for the development of renewable energy sector development were identified as below (Table $3)$.

The key aim of the survey was to gain information on the level of importance of the above factors. Thus for each of 
the factors, the experts were requested to indicate the level of significance for the advancement of renewable energy sector in Sri Lanka. The four point Likert scale was used to rate the level of importance. For example the participants were requested to select one of the following levels of importance, and interpret the explanation accordingly (Refer: Table 4).

The expected level of importance was calculated by multiplying the corresponding frequencies (f) with the weight (w) attributed and by dividing the sum by the number of respondents. The final results of the survey are summarized in table 5 .

The five factors that were ranked as "Very Important" were highlighted in Table 5. As part of the survey, the respondents were asked to justify their arguments pertaining to the ranking they gave for the questionnaire. The respective arguments are discussed in the following section of this paper.

Table 3. Key factors impact upon the development of NCRE Power Sector of Sri Lanka

\begin{tabular}{l|l}
\hline 01 & Public concern on the environmental impacts when choosing the energy sources. \\
02 & Growing energy intensive lifestyle of the public. \\
03 & Government policies pertaining to the renewable energy sector of the country \\
04 & Private and public sector participation in the renewable energy sector \\
05 & The cost of fossil based energy sources vs. cost of renewable energy options \\
06 & International pressure on emission of Greenhouse gasses \\
07 & Technical limitations in the national grid in absorbing electricty generated via renewable energy sources \\
08 & Global technological advancements which are conducive to renewable energy developments \\
\hline
\end{tabular}

Table 4. Likert scale was used in the questionnaire

\begin{tabular}{c|c|ccc}
\hline Level of Importance: & Very Important & Important & Less Important & Not Important \\
\hline Explanation & $\begin{array}{c}\text { This trend will } \\
\text { strongly contribute }\end{array}$ & $\begin{array}{c}\text { This trend will } \\
\text { moderately contribute }\end{array}$ & $\begin{array}{c}\text { This trend will have } \\
\text { low contribution }\end{array}$ & $\begin{array}{c}\text { The contribution of } \\
\text { this trend will be } \\
\text { negligible }\end{array}$ \\
\hline Weight & 4 & 3 & 2 \\
\hline
\end{tabular}

Table 5. Survey results on the key factors impact upon the development of NCRE Power Sector of Sri Lanka

\begin{tabular}{|c|c|c|}
\hline Key Factors & $\begin{array}{l}\text { Average } \\
\text { weight }\end{array}$ & $\begin{array}{l}\text { Expected level } \\
\text { of importance }\end{array}$ \\
\hline Public concern on the environmental impacts when choosing the energy sources. & 3.0 & Less Important \\
\hline Growing energy intensive lifestyle of the public. & 3.6 & Very Important \\
\hline Government policies pertaining to the renewable energy sector of the country & 3.6 & Very Important \\
\hline Private and public sector participation in the renewable energy sector & 3.6 & Very Important \\
\hline The cost of fossil based energy sources vs. cost of renewable energy options & 3.3 & Very Important \\
\hline International pressure on emission of Greenhouse gasses & 2.8 & Less Important \\
\hline $\begin{array}{l}\text { Technical limitations in the national grid in absorbing electricty generated via renewable energy } \\
\text { sources }\end{array}$ & 2.0 & Less Important \\
\hline Global technological advancements which are conducive to renewable energy developments & 3.7 & Very Important \\
\hline
\end{tabular}




\section{Conclusion and Recommendations}

The Kyoto protocol of the UN framework has reached the second commitment period, and protocol urged the Annex 1 parties to reduce GHG emissions by at least $18 \%$ below 1990 levels in the eight-year period from 2013 to 2020 (UNFCCC - Kyoto Protocol). Though developing countries do not have such obligations, international pressure on developed countries \& countries where their economies in transition urged the importance of taking early measures in reducing GHG emission. Based on the long term generation expansion plan of CEB, the thermal sources will dominate the Sri Lankan electricity generation sector. Among the greenhouse gasses that are listed under the Annex A of the Kyoto Protocol, Carbon dioxide $\left(\mathrm{CO}_{2}\right)$ is an inevitable outcome that would result in higher burning of thermal sources to generate electricity. Under the base case plan it is estimated that amount of $\mathrm{CO}_{2}$ that will be emitted by the end of 2020 will be 11,074,000 tons (CEB Long term generation expansion plan, 2011: 9-5). Knowing the fact that burning of fossil fuels for energy generation is the prime contributor to GHG emission it is essential to take immediate actions to strengthen the NCRE sector for better sustainable future.

\section{Recommendations to strengthening the NCRE sector}

Having understood the current situation Sri Lankan Government has already taken measures to promote renewable energy sector. The establishment of 'Sustainable Energy Authority', through an act of parliament (Act 35 of 2007) is one such measure (Ratnasiri, 2008:109). National Climate Change Policy of Sri Lanka, adopted in 2012 has included policy elements to explore the potential of clean and renewable energy sources and enhance their production, accessibility, and affordability (Ministry of Environment The National Climate Change Policy of Sri Lanka, 2012:7). Irrespective of policy measures that have already taken place the fact that Sri Lanka is falling behind the policy targets implies that we might need to switch our path in order to reach our targets in renewable energy.

Energy is important for social and economic development and crucial for individuals and communities in developing countries to meet their basic needs (Kolk and Buuse, 2012: 552). Thus as a rapidly developing nation, Sri Lanka should have a robust energy supplying system and renewable energy should not be a burden for the economy. Based on the current tariff system CEB is currently paying a premium price in order to attract the investors. Thus in order to strengthen the renewable energy sector of Sri Lanka and mitigate the emission of GHGs we should take a distinct approach. Renewable energy sources by nature distribute in more localize manner. Thus these localized energy resources should be harnessed via localized off-grid solutions. Further though the electricity is our main concern, renewables sources can be more effectively used in addressing the direct energy needs. Once such example would be the use of solar thermal for cooking and for drying which can be used in industries or in households. Net metering is one such solution that we could look in to. Net metering is not only for solar (though it is the most convenient energy resource), but it is open for wind or biomass sources as well.

One of the key concerns in Sri Lankan renewable energy sector is the technology. But the rest of the world is moving so fast in terms of technology improvements and simultaneously the cost is drastically falling. Interestingly, developing countries and emerging markets tend to play a prominent role in new capacity addition over the last few years (REN21 Global Status Report, 2012:16). In terms of technology development our neighboring countries have surpassed the OECD countries. Out of the world's top ten turbine manufactures (who are catering to $77 \%$ of the global market) $50 \%$ shared by Chinese and Indian companies. Out of the top 15 solar PV module manufacturers who accounted for half of the world production, 11 companies hailed from Asia (REN21 Global Status Report, 2013: 43-52). Rapid escalation of these neighboring countries teaches us a valuable lesson. Though we see these improvements as a radical development, they did not happen overnight. Other than the correct policies, effective and efficient transfers of technology from the technologically advanced countries were the secret behind their success. Technology transfer is seen as a cornerstone in reaching a global solution to climate change (Lema and Lema, 2012: 2). But we need to be careful in transfer of Renewable Energy technologies to our country as it should not be merely acquisition of hardware. The technology transfer should enable us to acquire, adapt, deploy and diffuse renewable energy technologies from overseas and further innovate as a result of the capabilities acquired through the technology transfer process (Pueyo and Linares, 2012: 7). Technology development and transfer are included as priorities in both the United Nations Framework Convention on Climate Change (UNFCCC) and its Kyoto Protocol (UNFCCC-The Contribution of the Cleaner Development Mechanism to Technology Transfer, 2010:12). However, the UNFCCC processes have had a limited success in promoting mechanisms such as Cleaner Development Mechanism (CDM), mainly due to their disconnection with national enabling factors and to their homogeneous approach for all developing countries (Pueyo and Linares, 2012: 3). Thus Sri Lanka should harness the maximum benefit out of such mechanisms which are ready available for developing countries, and while doing so we must be careful to strengthen our capabilities in parallel.

\section{REFERENCES}

[1] Benioff, R. et al. (2010). Strengthening Clean Energy Technology Cooperation under the UNFCCC: Steps toward Implementation. NREL, ECN and URC.

[2] Ceylon Electricity Board, (2011), 'Long Term Generation Expansion Plan', CEB, Colombo.

[3] Kolk, A. and van den Buuse, D. (2012), 'In search of viable 
business models for development: sustainable energy in developing countries', Corporate Governance, Vol. 12, no. 4, pp. 551-567.

[4] Lema, R. and Lema, A. (2012) 'Technology transfer? The rise of China and India in green technology sectors', Innovation and Development, Vol. 2, no. 1, pp.23-44.

[5] Ministry of Environment, (2012), 'The National Climate Change Policy of Sri Lanka', Colombo.

[6] Public Utility Commission of Sri Lanka, (2012), 'Proposed Non-Conventional Renewable Energy Tariffs', [Online], Available at: $<$ http://www.pucsl.gov.lk/english/wp-content/u ploads/2012/12/Decision-on-NCRE-Purchase-Tariffs-2012-2 013-Web-Vesion.pdf $>$ [Accessed 01 September 2013].

[7] Pueyo, A. and Linares, P. (2012) 'Renewable Technology Transfer to Developing Countries: One Size Does Not Fit All', IDS Working Papers, Vol.2012, no.412, pp.1-39.

[8] RAM, (2012), 'Sri Lankan Power sector-Firing the rain', [e-book] RAM Rating (Lanka).

[9] Ranasinghe, D. M. H. S. K. (2012). Climate Change MitigationSri Lanka's Perspective. In Proceedings of International Forestry and Environment Symposium, Vol.15, pp. 290-296.

[10] Ratnasiri, J., (2008), 'Alternative energy - prospects for Sri Lanka', Journal of the National Science Foundation of Sri
Lanka, 36(Special Issue):p.89-114.

[11] REN21 (2012), Renewables 2012 Global Status Report, Paris: Renewable Energy Policy Network for 21st Century, REN21 Secretariat.

[12] REN21 (2013), Renewables 2013 Global Futures Report, Paris: Renewable Energy Policy Network for 21st Century, REN21 Secretariat.

[13] REN21 (2013), Renewables 2013 Global Status Report, Paris: Renewable Energy Policy Network for 21st Century, REN21 Secretariat.

[14] SLSEA, (2011) A Guide To The Project Approval Process For On-Grid Renewable Energy Project Development, Colombo: Sri Lanka Sustainable Energy Authority. Colombo. Available at:

$<$ http://www.ram.com.lk/reports/power_sector_update.pdf $>$ [Accessed 07 August 2013].

[15] SLSEA, (2011), 'Sri Lanka Energy Balance', Sri Lanka Sustainable Energy Authority, Colombo.

[16] UNFCCC - Kyoto Protocol, (2013), [Online], Available at: http://unfccc.int/kyoto_ protocol/items/2830.php [Accessed 15 September 2013].

[17] UNFCCC, (2010) The Contribution of the Clean Development Mechanism under the Kyoto Protocol to Technology Transfer. 